\title{
RhoA/rock signaling mediates peroxynitrite- induced functional impairment of Rat coronary vessels
}

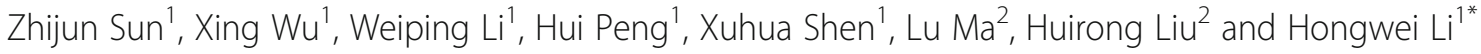

\begin{abstract}
Background: Diabetes-induced vascular dysfunction may arise from reduced nitric oxide (NO) availability, following interaction with superoxide to form peroxynitrite. Peroxynitrite can induce formation of 3-nitrotyrosine-modified proteins. RhoA/ROCK signaling is also involved in diabetes-induced vascular dysfunction. The study aimed to investigate possible links between Rho/ROCK signaling, hyperglycemia, and peroxynitrite in small coronary arteries.

Methods: Rat small coronary arteries were exposed to normal (NG; 5.5 mM) or high (HG; $23 \mathrm{mM}$ ) D-glucose. Vascular ring constriction to $3 \mathrm{mM}$ 4-aminopyridine and dilation to $1 \mu \mathrm{M}$ forskolin were measured. Protein expression (immunohistochemistry and western blot), mRNA expression (real-time PCR), and protein activity (luminescence-based G-LISA and kinase activity spectroscopy assays) of RhoA, ROCK1, and ROCK2 were determined.

Results: Vascular ring constriction and dilation were smaller in the HG group than in the NG group $(P<0.05)$; inhibition of RhoA or ROCK partially reversed the effects of HG. Peroxynitrite impaired vascular ring constriction/ dilation; this was partially reversed by inhibition of RhoA or ROCK. Protein and mRNA expressions of RhoA, ROCK1, and ROCK2 were higher under HG than NG $(P<0.05)$. This $\mathrm{HG}$-induced upregulation was attenuated by inhibition of RhoA or ROCK $(P<0.05)$. HG increased RhoA, ROCK1, and ROCK2 activity $(P<0.05)$. Peroxynitrite also enhanced RhoA, ROCK1, and ROCK2 activity; these actions were partially inhibited by $100 \mu \mathrm{M}$ urate (peroxynitrite scavenger). Exogenous peroxynitrite had no effect on the expression of the voltage-dependent $\mathrm{K}^{+}$channels 1.2 and 1.5 .
\end{abstract}

Conclusions: Peroxynitrite-induced coronary vascular dysfunction may be mediated, at least in part, through increased expressions and activities of RhoA, ROCK1, and ROCK2.

Keywords: Peroxynitrite, RhoA/ROCK, Hyperglycemia, Coronary artery, Vasoconstriction, Vasodilation

\section{Background}

Diabetes mellitus (DM) is associated with disturbances in coronary arterial function that contribute to the detrimental effects of DM on the heart. Indeed, DM has been reported to cause dysfunction of endothelial-dependent vasodilation of small coronary arteries [1-3], even during the early stages of the disease [4]. This impairment in the relaxation of coronary vessels may involve, at least in part, reduced availability of nitric oxide $(\mathrm{NO})[5,6]$. In turn, this is thought to be due to a decrease in $\mathrm{NO}$ synthase (NOS) activity $[7,8]$, as well as to the

\footnotetext{
* Correspondence: Ihw19656@sina.com

${ }^{1}$ Department of Heart Center, Capital Medical University Affiliated Beijing

Friendship Hospital, Beijing, China

Full list of author information is available at the end of the article
}

interaction of $\mathrm{NO}$ with superoxide to generate peroxynitrite $\left(\mathrm{ONOO}^{-}\right)$[9]. Peroxynitrite is a powerful oxidizing agent that causes nitration of aromatic amino acid residues, forming 3-nitrotyrosine (3-NT)-modified proteins. Enhanced 3-NT formation has been reported in an animal model of DM [10]. Peroxynitrite is known to participate in DM-induced endothelial dysfunction [11, 12]. Indeed, studies in DM models showed that increases in peroxynitrite levels were associated with vascular permeability and impaired vasorelaxation [13]. It has also been shown that peroxynitrite suppresses eNOS expression through RhoA activation, leading to endothelial dysfunction [11]. Peroxynitrite leads to the formation of nitrotyrosine in the artery walls, which is directly toxic to endothelial cells and leads to endothelial dysfunction 
[12]. The presence of nitrotyrosine is associated with microvascular anomalies in DM, and correlate with blood glucose [14].

RhoA is a small, guanosine-5'-triphosphate binding protein, bound to the plasma membrane. Upon stimulation, RhoA activates RhoA-associated protein kinase (ROCK), of which there are two isoforms (ROCK1 and ROCK2) with an overall homology of $65 \%$ [15]. RhoA/ROCK signaling regulates numerous cellular processes, including gene transcription, organization of the actin cytoskeleton, and cell contraction, adhesion, motility, proliferation, and differentiation [16]. The RhoA/ROCK signaling pathway has been involved in several pathological conditions $[16,17]$ including hypertension [18, 19], atherosclerosis [20], stroke [21], coronary vasospasm [22], angina [23], ischemia-reperfusion injury [24], and heart failure [25, 26]. There is strong evidence that DM increases the expressions and activities of RhoA and ROCK in various tissues, and that the resulting phosphorylation of downstream targets enhances the contraction of vascular smooth muscle cells [27-33].

Potassium channels regulate $\mathrm{K}^{+}$efflux and are major regulators of membrane potential of vascular smooth muscle cells. Therefore, $\mathrm{K}^{+}$channel activity is an important factor involved in the regulation of vasoconstriction and blood vessel diameter [34]. Voltage-dependent $\mathrm{K}^{+}$channels $\left(\mathrm{K}_{\mathrm{v}}\right)$ limit membrane depolarization to maintain the vascular tone [35]. $\mathrm{K}_{\mathrm{v}} 1.2$ and $\mathrm{K}_{\mathrm{v}} 1.5$ are subunits that are expressed in vascular smooth muscle cells [35]. Many vasoconstrictors act through the inhibition of $\mathrm{K}^{+}$channel activity [35].

However, the precise mechanisms by which peroxynitrite impairs the function of small coronary arteries remain largely unknown. The aim of the present study was to explore whether the RhoA/ROCK signaling pathway and $\mathrm{K}_{\mathrm{V}}$ are involved in mediating peroxynitrite-induced impairment of rat small coronary arteries.

\section{Methods}

\section{Animals}

Male Sprague-Dawley rats (age, 7-8 weeks; weight, $180-220$ g) were provided by Vital River Laboratory Animal Technology Co., Ltd. (Beijing, China). Animals were housed under specific pathogen-free conditions and given free access to food and water. All animal experiments were performed in accordance with the Guidelines for the Care and Use of Laboratory Animals, Ministry of Science and Technology (Beijing, China). The study was approved by the Animal Care and Use Committee of Beijing Friendship Hospital, Capital Medical University (Beijing, China).

\section{Preparation of isolated rat small coronary arteries}

Rats were anesthetized with chloral hydrate $(0.5 \mathrm{~mL} /$ 100 g i.p.) and received heparin $(2500 \mathrm{U} / \mathrm{kg})$ to inhibit blood clot formation. The heart was removed and placed in HEPES-buffered (Hanks) solution at $4{ }^{\circ} \mathrm{C}$. The cardiac apex and ascending aorta were fixed using pins, and the left auricle was identified under a $2 \times 10$ stereoscopic microscope (with a halogen lamp as a cold light source; Nikon, Tokyo, Japan). The left anterior descending branch of the coronary artery was identified under the left auricle, and small coronary arteries with diameters $\leq 200 \mu \mathrm{m}$ were isolated rapidly as vascular rings of about 2 -mm. The endothelium was denuded with air, and denudation was verified by failure to dilate in response to $1 \mu \mathrm{M}$ acetylcholine.

For the experiments, the isolated vascular rings were incubated in 6-well dishes at $37{ }^{\circ} \mathrm{C}$ for $24 \mathrm{~h}$ with Dulbecco's modified Eagle's medium (DMEM; Gibco, USA) supplemented with $20 \%$ fetal calf serum (Gibco, USA), $100 \mathrm{U} / \mathrm{mL}$ penicillin $\mathrm{G}$, and $100 \mathrm{mg} / \mathrm{mL}$ streptomycin. The vascular rings were divided into the following groups: normal glucose (NG group, $5.5 \mathrm{mM} \mathrm{D}$-glucose), L-glucose (LG group, $5.5 \mathrm{mM}$ D-glucose plus $17.5 \mathrm{mM}$ L-glucose), or high glucose (HG group, $23 \mathrm{mM}$ D-glucose). In experiments of pharmacologic disruption of the RhoA/ROCK pathway, vascular rings of the HG group were pre-treated for $16 \mathrm{~h}$ with either the RhoA inhibitor, C3 transferase $(1 \mu \mathrm{g} / \mathrm{ml}, \mathrm{HG}+\mathrm{C} 3$ group; Cytoskeleton, USA), or the ROCK inhibitor, Y-27632 $(10 \mu \mathrm{M}$, HG + Y-27632 group; Sigma-Aldrich, St. Louis, MO, USA), followed by culture in high glucose medium. In experiments investigating the effects of exogenous peroxynitrite, vascular rings of the NG group were incubated $\left(37^{\circ} \mathrm{C}, 24 \mathrm{~h}\right)$ in the presence of additional agents: $5 \mu \mathrm{M}$ peroxynitrite $\left(\mathrm{ONOO}^{-}\right.$group), $5 \mu \mathrm{M}$ decomposed peroxynitrite (DC-ONOO ${ }^{-}$group), or $5 \mu \mathrm{M}$ peroxynitrite plus $100 \mu \mathrm{M}$ urate $\left(\mathrm{ONOO}^{-}+\right.$urate group). Peroxynitrite was synthesized according to published methods, and determined spectrophotometrically using the reported extinction coefficient for peroxynitrite (1670/M/ $\mathrm{cm})$ [36]. Before each application, the stock solution was diluted in $1 \mathrm{mM} \mathrm{NaOH}$ and rapidly added to the chamber to achieve a final concentration of $5 \mu \mathrm{M}$. Decomposed peroxynitrite was made by leaving peroxynitrite at room temperature for at least $2 \mathrm{~h}$. Urate (Sigma-Aldrich) was used as a scavenger of peroxynitrite.

\section{Contraction and relaxation of vascular rings in response to 4-aminopyridine and forskolin}

After incubation with the appropriate experimental solution, each coronary artery ring was threaded onto two tungsten filaments (each with a diameter of $40 \mu \mathrm{m}$ ) and fixed to the bath transducers of a Multi Wire Myograph System-610 M (DMT, Aarhus, Denmark). The vascular 
ring was bathed in HEPES-buffered solution (8.415 g/l $\mathrm{NaCl}, 0.432 \mathrm{~g} / \mathrm{l} \mathrm{KCl}, 0.244 \mathrm{~g} / \mathrm{l} \mathrm{MgCl}_{2} \cdot 6 \mathrm{H}_{2} \mathrm{O}, 0.277 \mathrm{~g} / \mathrm{l}$ $\mathrm{CaCl}_{2}, 2 \mathrm{~g} / \mathrm{l}$ glucose, $1.1915 \mathrm{~g} / \mathrm{l}$ HEPES) gassed with $100 \% \mathrm{O}_{2}$ and maintained at $37^{\circ} \mathrm{C}$. As a standardization procedure, the transmural pressure of the vascular ring was set to a baseline value of $13.33 \mathrm{kPa}(100 \mathrm{mmHg})$; this was achieved by adjusting the tension of the vascular ring to the desired value, with the aid of the following equations:

$$
\begin{aligned}
& \mathrm{P}_{\mathrm{i}}=2 \pi \mathrm{T}_{\mathrm{i}} / \mathrm{IC}_{\mathrm{i}} \\
& \mathrm{T}_{\mathrm{i}}=\mathrm{F}_{\mathrm{i}} / 2 \mathrm{~L} \\
& \mathrm{IC}_{\mathrm{i}}=205.6+2 \mathrm{X}_{\mathrm{i}}
\end{aligned}
$$

where:

$\mathrm{P}_{\mathrm{i}}(\mathrm{kPa})=$ effective transmural pressure

$\mathrm{T}_{\mathrm{i}}(\mathrm{mN} / \mathrm{mm})=$ vascular ring tension per unit length

$\mathrm{IC}_{\mathrm{i}}(\mu \mathrm{m})=$ vascular ring inner perimeter

$\mathrm{F}_{\mathrm{i}}(\mathrm{mN})=$ total tension of the vascular ring, determined by the myography system

$\mathrm{X}_{\mathrm{i}}(\mu \mathrm{m})=$ distance between the two tungsten wires, determined by the myography system

$\mathrm{L}(\mathrm{mm})=$ vascular ring length, determined with a dissecting microscope and micrometer

Experiments were performed after an equilibration period of 60-90 min, during which the bathing medium was replaced every $15-20$ min with pre-heated $\left(37^{\circ} \mathrm{C}\right)$ HEPES-buffered solution. The tension changes of each vascular ring were determined automatically by the myography system and recorded by a computer running the Chart 5.5 software (ADInstruments, Dunedin, New Zealand). Before examining the responses of the vascular rings to vasoactive substances, the rings were exposed repeatedly to $120 \mathrm{mM} \mathrm{KCl}$ until the contraction amplitude differences for three successive applications of $\mathrm{KCl}$ were less than $10 \%$; tension was then allowed to stabilize for $30 \mathrm{~min}$ before vasoactive substances were administered. Contraction was measured in response to a range of concentrations (0.1-3 $\mathrm{mM})$ of 4aminopyridine (4-AP, Sigma-Aldrich), a blocker of the $\mathrm{K}_{\mathrm{v}} 1 \mathrm{~K}^{+}$channels. Relaxation in response to $1 \mu \mathrm{M}$ forskolin (an adenylyl cyclase activator; Sigma-Aldrich) was also assessed.

\section{Isolation of vascular smooth muscle cells from rat small coronary arteries}

Small coronary arteries with diameters $\leq 200 \mu \mathrm{m}$ were obtained as described above. Coronary vascular smooth muscle cells (VSMCs) were isolated enzymatically. The adventitia was dissected from the small coronary arteries, and the vessel washed three times with sterile Hanks' buffered salt solution. The vessel was incubated for $10 \mathrm{~min}$ at room temperature with $1 \mathrm{~mL}$ of phosphate- buffered saline (PBS) containing $0.1 \%$ bovine serum albumin (BSA), and subsequently digested for $10 \mathrm{~min}$ at $37{ }^{\circ} \mathrm{C}$ in $1 \mathrm{~mL}$ of PBS containing $0.15 \%$ papain, $0.1 \%$ dithioerythritol (DTE), and $0.1 \%$ BSA. The vessel was then incubated for $10 \mathrm{~min}$ at $37^{\circ} \mathrm{C}$ with $1 \mathrm{~mL}$ of PBS containing $0.2 \%$ collagenase, $0.05 \%$ elastase, and $0.1 \%$ soybean trypsin inhibitor. Subsequently, $5 \mathrm{~mL}$ of DMEM containing $20 \%$ fetal bovine serum (FBS) were added to stop digestion. The mixture was centrifuged at $1000 \mathrm{rpm}$ for $7 \mathrm{~min}$, and the supernatant was discarded. The pellet was washed with sterile PBS and resuspended in $4-5 \mathrm{~mL}$ of culture medium. The resuspended cells were seeded into culture flasks and cultured for $24 \mathrm{~h}$ (DMEM containing $20 \% \mathrm{FBS}$ ). When the cells were fully adherent, as determined under an inverted microscope, the culture medium was changed to DMEM containing $10 \%$ FBS, $100 \mathrm{U} / \mathrm{mL}$ of penicillin $\mathrm{G}$, and $100 \mu \mathrm{g} / \mathrm{mL}$ of streptomycin. Primary VSMCs were cultured for 7 days to reach a logarithmic phase. The cell passages were performed when cell coverage reached $80 \%$. Culture medium was discarded, and the cells were washed with sterile PBS and digested with $1 \mathrm{~mL}$ of $0.25 \%$ trypsin (2$3 \mathrm{~min}, 37^{\circ} \mathrm{C}$ ). Digestion was terminated with culture medium containing FBS when the morphology of 80 $90 \%$ of the cells changed from spindle-shaped to round. The digested cells were seeded into flasks for culture, and passages could be performed after 3-4 days. Cells were then used for glucose exposure experiments.

Smooth muscle cells were identified by immunofluorescence. Single-cell suspensions were seeded into dishes containing coverslips, and a coverslip covered with a monolayer of cells was fixed with $95 \%$ pre-cooled ethanol for $30 \mathrm{~min}$. After three washes with PBS, the cells were incubated with the primary antibody (mouse antirat alpha-smooth muscle actin polyclonal antibody; Santa Cruz Biotechnology, Santa Cruz, CA, USA) for $30 \mathrm{~min}$ at $37{ }^{\circ} \mathrm{C}$. After three washes with PBS, the cells were incubated with the secondary antibody (IgG-FITClabeled chicken anti-mouse secondary antibody; Santa Cruz Biotechnology) for $30 \mathrm{~min}$ at $37{ }^{\circ} \mathrm{C}$. After washing with PBS (three times), 4',6-diamidino-2-phenylindole (DAPI) was added for 2 min (to stain the nuclei). After three washes with PBS, the coverslip was mounted onto a slide with mounting medium, and the cells were observed using a fluorescence microscope (Nikon, Tokyo, Japan).

\section{Real-time PCR for mRNA expression}

Total RNA of cultured coronary vascular smooth muscle cells was extracted with Trizol (Invitrogen, Carlsbad, CA, USA), and RNA concentration and purity were determined using an ultraviolet spectrophotometer. Total RNA $(1 \mu \mathrm{g})$ was reverse-transcribed into cDNA with reverse transcriptase (Shanghai Jierdun Biotech Co. Ltd., 
Shanghai, China), according to the manufacturer's protocol. The expressions of RhoA, ROCK1, ROCK2, $\mathrm{K}_{\mathrm{v}} 1.2$, and $\mathrm{K}_{\mathrm{v}} 1.5$ mRNA were assessed by real-time polymerase chain reaction (PCR) of the cDNA $(2 \mu \mathrm{g})$, using an $\mathrm{ABI}$ Step One Plus Real-Time-PCR System (Applied Biosystems, Foster City, CA, USA), SYBR Green Master Mix (Applied Biosystems), and the following primers (Invitrogen):

RhoA (103 bp):

F: 5' -CATCCCAGAAAAGTGGACTCCA- 3'

R: 5' -CCTTGTGTGCTCATCATTCCG- 3'

ROCK1 (113 bp):

F: 5' -GAATGACATGCAAGCGCAAT- 3'

R: 5' -GTCCAAAAGTTTTGCACGCA- 3'

ROCK2 (150 bp):

F: 5' -GAAACAACTGGATGAAGCTAATGC- 3'

R: 5' -GTTTCAAGCAGGCAGTTTTTATCTT- 3'

$\mathrm{K}_{\mathrm{v}} 1.2:$

F: 5' CGT CAG CTT CTG TCT GGA AAC C $3^{\prime}$

R: 5' TGC ATG TCC TCG TTC TCA TCC $3^{\prime}$

$\mathrm{K}_{\mathrm{v}} 1.5$ :

F: $5^{\prime}$-CCTGTCCCCGTCATCGTCTC- $3^{\prime}$

R: 5' -ACCTTCCGTTGACCCCCTGT- 3'

GAPDH (75 bp):

F: 5' -CCTGCCAAGTATGATGACA- 3'

R: 5' - GTAGCCCAGGATGCCC - 3'

GAPDH was used as a reference to obtain the relative fold changes for the target genes, using the comparative $\mathrm{Ct}$ method. Relative mRNA expressions were estimated using the $2^{-\triangle \Delta C T}$ method.

\section{Immunohistochemistry}

Standard immunohistochemistry protocols were applied to small coronary arteries treated for $24 \mathrm{~h}$ with the various experimental solutions, in order to determine the protein expression levels of RhoA, ROCK1, and ROCK2. The small coronary arteries were fixed with $4 \%$ paraformaldehyde and sectioned $(4 \mu \mathrm{m})$. The following primary antibodies $(100 \mu \mathrm{L})$ were used: anti-RhoA (1:200 dilution; BS1782; Bioworld Technology Inc., St. Louis Park, MN, USA), anti-ROCK1 (1:200 dilution; sc-6055; Santa Cruz Biotechnology), and anti-ROCK2 (1:250 dilution; sc-1851; Santa Cruz Biotechnology). The secondary antibody was biotinylated goat anti-rabbit IgG (Beyotime Institute of Biotechnology, Shanghai, China). Sections were visualized with diaminobenzidine (DAB; Shanghai Jierdun Biotech) and counterstained with hematoxylin and eosin (H\&E). Images were captured with a digital camera (Nikon) and analyzed using the IMS imaging processing system (Shanghai Jierdun Biotech). Positively stained regions were counted and analyzed. Cardiomyocytes were excluded.

\section{Immunoprecipitation}

Adherent cells were cultured in 10-cm dishes for protein isolation. The cell culture medium was discarded. The cells were washed with PBS, and $1 \mathrm{~mL}$ of lysis buffer was added for cell lysis. A $200-1000 \mu \mathrm{L}$ sample containing about $200-1000 \mu \mathrm{g}$ of protein was mixed with $1 \mu \mathrm{g}$ of IgG (that shared the same host species as the IgG used in the immunoprecipitation) and $20 \mu \mathrm{L}$ of protein A/G agarose. The mixture was incubated at $4{ }^{\circ} \mathrm{C}$ for 30 $120 \mathrm{~min}$, with gentle agitation, and then centrifuged at $1000 \mathrm{~g}$ for $5 \mathrm{~min}$. The supernatant was isolated for subsequent protein immunoprecipitation. Primary antibodies $(0.2-2 \mu \mathrm{g})$ against RhoA (1:400), ROCK1 (1:400), ROCK2 (1:400), $\mathrm{K}_{\mathrm{v}} 1.2(1: 500)$, or $\mathrm{K}_{\mathrm{v}} 1.5$ (1:500) were added to the supernatant, and the mixture was incubated overnight at $4{ }^{\circ} \mathrm{C}$ with gentle agitation. Then, $20 \mu \mathrm{L}$ of thoroughly resuspended protein $\mathrm{A} / \mathrm{G}$ agarose was added, and this was incubated for a further $1-3 \mathrm{~h}$ at $4{ }^{\circ} \mathrm{C}$, with gentle agitation. The mixture was centrifuged at $1000 \mathrm{~g}$ for $5 \mathrm{~min}$ or transiently at high speed, and the supernatant was discarded. The pellet was washed five times with $0.5-1 \mathrm{~mL}$ of lysis buffer (used for protein isolation) or PBS, and resuspended in 20-40 $\mu \mathrm{L}$ of $1 \times$ SDS-PAGE loading buffer. After transient centrifugation at high speed, the sample was boiled at $100{ }^{\circ} \mathrm{C}$ for $3-5 \mathrm{~min}$. Partial or total samples were used for protein quantification or SDS-PAGE electrophoresis, or stored at $-20^{\circ} \mathrm{C}$ for later use.

\section{Western blotting for protein expression}

Total protein was extracted from artery rings, and the protein concentration determined using a bicinchoninic acid (BCA) protein assay kit (Thermo Fisher Scientific, Waltham, MA, USA). Immunoblotting was performed with the following primary antibodies: anti-RhoA (Bioworld), anti-ROCK1 (Santa Cruz Biotechnology), antiROCK2 (Santa Cruz Biotechnology), anti- $\mathrm{K}_{\mathrm{v}} 1.2$, or anti$\mathrm{K}_{\mathrm{v}}$ 1.5. HRP-conjugated anti-rabbit secondary antibody was used at a dilution of 1:2000. Detection of GAPDH (diluted 1:1500; \#5471; Cell Signaling Technology, Danvers, MA, USA) served as an internal loading control. All blots were scanned with the LabWorks image processing system (UVP Inc., Upland, CA, USA). Protein band pixel 
values were calculated using Gel-pro Analyzer 4.0 (Media Cybernetics Inc., Rockville, MD, USA).

\section{Measurement of RhoA and ROCK activities}

RhoA activation was measured using the luminescencebased G-LISA Activation Assay kit (Cytoskeleton Inc., Denver, CO, USA), according to the manufacturer's instructions. Values were normalized to the protein content using a colorimetric assay (Bio-Rad Laboratories, Hercules, CA, USA), according to the manufacturer's recommendations. ROCK1 and ROCK2 activities were detected using the Kinase Activity Spectroscopy Kit (GMS50184.3 for ROCK1 and GMS50184.1 for ROCK2; Genmed Scientific Inc., Arlington, MA, USA), according to the manufacturer's instructions.

\section{Statistical analysis}

Continuous data were expressed as means \pm standard deviation (SD). Statistical analyses were performed using SPSS 18.0 (IBM, Armonk, NY, USA). Comparisons between groups were performed using one-way analysis of variance (ANOVA) or the Student's $t$-test, as appropriate. The Bonferroni correction was applied when comparing three or more groups. $P$ values $<0.05$ were considered statistically significant.

\section{Results}

Impairment of vascular ring contraction and dilation by high glucose or peroxynitrite may involve RhoA/ROCK signaling

Figure 1a presents concentration-response curves showing the contractile responses of vascular rings in the various experimental groups treated with 4-AP. Maximal contraction in response to $3 \mathrm{mM}$ 4-AP, was significantly smaller in the LG $(2.08 \pm 0.17 \mathrm{mN})$ and HG $(1.37 \pm 0.22$ $\mathrm{mN})$ groups than in the NG group $(3.15 \pm 0.31 \mathrm{mN})(P$ $<0.05 ; n=6$ ). Interestingly, inhibition of RhoA or ROCK partially reversed this effect of high glucose: the maximal contractile response of rings treated with 4-AP was significantly larger in the $\mathrm{HG}+\mathrm{C} 3(2.13 \pm 0.09 \mathrm{mN})$ and HG $+\mathrm{Y}-27632(2.02 \pm 0.16 \mathrm{mN})$ groups than in the HG group $(P<0.05 ; n=6)$. Similar observations were made in experiments using forskolin (Fig. 1b): dilation in response to $1 \mu \mathrm{M}$ forskolin was significantly reduced in the LG $(39.47 \pm 1.32 \%)$ and HG $(35.20 \pm 1.98 \%)$ groups compared with the NG group (48.97 $\pm 1.77 \%)$, and was higher in both the HG + C3 $(39.80 \pm 1.59 \%)$ and $\mathrm{HG}+$ Y-27632 $(39.68 \pm 1.57 \%)$ groups than in the HG group $(P<0.05 ; n=6)$.

Additional experiments were carried out to determine whether exogenous peroxynitrite $(5 \mu \mathrm{M})$ could mimic these effects of high glucose. The contractile response of rings treated with $3 \mathrm{mM}$ 4-AP was significantly reduced in the $\mathrm{ONOO}^{-}$group $(1.54 \pm 0.21 \mathrm{mN})$ compared with the NG group $(3.15 \pm 0.31 \mathrm{mN})(P<0.05 ; n=6)$, but $\mathrm{DC}-\mathrm{ONOO}^{-}$was without effect $(2.95 \pm 0.26 \mathrm{mN})$. Furthermore, the attenuation of contraction by ONOO- was inhibited (albeit not completely) by urate $(2.39 \pm 0.18$ $\mathrm{mN}), \mathrm{C} 3$ transferase $(2.17 \pm 0.15 \mathrm{mN})$, and $\mathrm{Y}-27632$ $(2.27 \pm 0.10 \mathrm{mN})\left(\mathrm{P}<0.05\right.$ compared with the $\mathrm{ONOO}^{-}$ group; $n=6)$ (Fig. 1c). Similarly, relaxation to forskolin was significantly smaller in the $\mathrm{ONOO}^{-}$group $(36.37 \pm$ $1.80 \%)$ than in the NG $(48.97 \pm 1.77 \%)$, $\mathrm{DC}^{-\mathrm{ONOO}^{-}}$ $(48.55 \pm 1.64 \%), \quad \mathrm{ONOO}^{-}+$urate $\quad(44.17 \pm 1.14 \%)$, $\mathrm{ONOO}^{-}+\mathrm{C} 3(42.02 \pm 1.73 \%)$, and $\mathrm{ONOO}^{-}+\mathrm{Y}-27632$ $(41.22 \pm 1.53 \%)$ groups $(\mathrm{P}<0.05 ; \mathrm{n}=6)($ Fig. $1 \mathrm{~d})$.

\section{Treatment with high glucose increases protein} expressions of RhoA, ROCK1, and ROCK2 detected by immunohistochemistry in denuded vessels

Figure 2 shows representative images obtained from immunohistochemistry experiments carried out to detect the protein expressions of RhoA, ROCK1, and ROCK2 in the various groups. Quantitative analyses of the immunohistochemistry data are shown in Fig. 3. Protein expressions of RhoA, ROCK1, and ROCK2 were significantly higher in the HG group than in the NG group ( $P$ $<0.05 ; n=3$ ). Importantly, inhibition of RhoA (C3 transferase) or ROCK (Y-27632) significantly attenuated the upregulation of ROCK1 and ROCK2 induced by high glucose, while Y-27632 inhibited the upregulation of RhoA $(P<0.05 ; n=3)$. This suggests that an increase in RhoA/ROCK signaling induced by high glucose can in turn feedback to upregulate the protein expressions of RhoA, ROCK1, and ROCK2.

Treatment with high glucose increases $\mathrm{mRNA}$ and protein expressions of RhoA, ROCK1, and ROCK2 detected by real-time $P C R$ and Western blotting

The mRNA expression of RhoA, ROCK1, and ROCK2, detected using real-time PCR, was significantly enhanced by high glucose $(P<0.05 ; n=5$; Fig. 4a-c). No significant effects of exogenous peroxynitrite were observed (Fig. $4 \mathrm{~d}-$ f), although a trend toward a small increase in expression could not be excluded. Consistent with the immunohistochemistry data, high glucose significantly enhanced the protein expressions of RhoA, ROCK1, and ROCK2 measured using western blotting $(P<0.05 ; n=5$; Fig. 5$)$.

Treatment with high glucose or exogenous peroxynitrite increases the activity of RhoA, ROCK1, and ROCK2

Further studies were undertaken to determine whether the high glucose-induced upregulation of RhoA, ROCK1, and ROCK2 expression translated into enhanced activities. As shown in Fig. 6a-c, treatment with high glucose was associated with significant increases in RhoA, ROCK1, and ROCK2 activity $(P<0.05 ; n=5)$. Interestingly, $5 \mu \mathrm{M}$ peroxynitrite (but not decomposed peroxynitrite) 


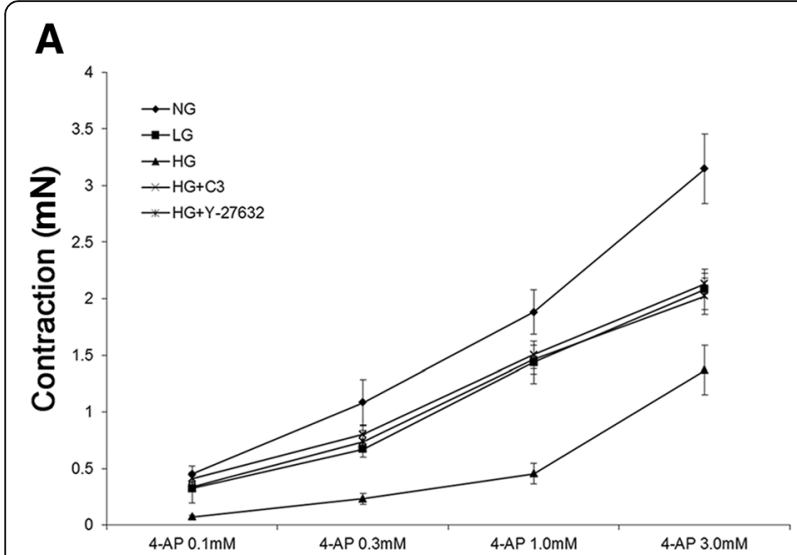

B
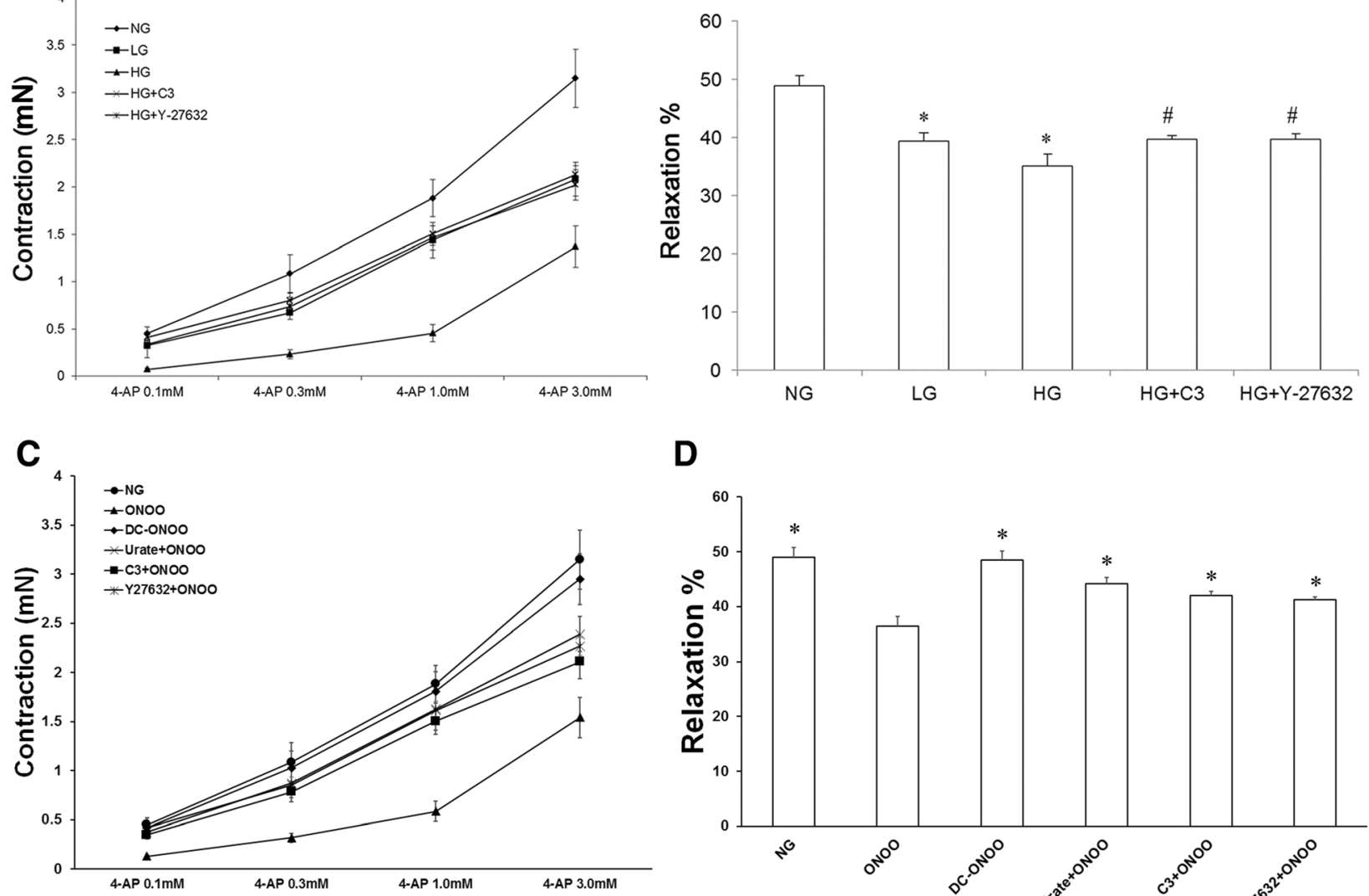

D

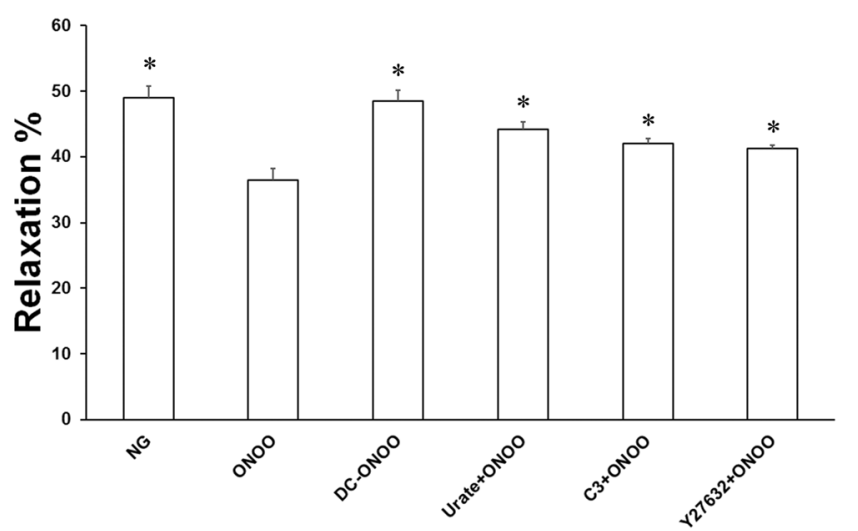

Fig. 1 Impairment of vascular ring contraction and dilation by high glucose involves RhoA/ROCK signaling. a Concentration-response curves showing the contractile responses of rat small coronary artery vascular rings treated with 4-AP (a voltage-gated $\mathrm{K}^{+}$channel blocker; $0.1-3 \mathrm{mM}$ ) under various experimental conditions. Treatment with high glucose (23 mM D-glucose) was associated with attenuation of contraction of rings treated with 4-AP (compared with 5.5 mM D-glucose) that was partially reversed by C3 transferase (a RhoA inhibitor) and Y-27632 (a ROCK inhibitor). b Rat small coronary artery vascular rings treated with high glucose (23 mM D-glucose) showed an impairment of dilation (compared with $5.5 \mathrm{mM}$ D-glucose) in response to $1 \mu \mathrm{M}$ forskolin (adenylyl cyclase activator); this impairment was partially reversed by C3 transferase and Y-27632. Data are shown as mean \pm SD $(n=6) .{ }^{*} P<0.05$ vs. NG. ${ }^{*} P<0.05$ vs. HG. c Concentration-response curves showing the contractile responses of rat small coronary artery vascular rings to 4-AP (a voltage-gated $\mathrm{K}^{+}$channel blocker; 0.1-3 mM) under various experimental conditions. Treatment with peroxynitrite $(5 \mu \mathrm{M}$ peroxynitrite) was associated with attenuation of contraction of rings treated with 4-AP (compared with $5.5 \mathrm{mM}$ D-glucose and $5 \mu \mathrm{M}$ decomposed peroxynitrite) that was partially reversed by urate, C3 transferase, and Y-27632. $\mathbf{d}$ Rat coronary small coronary artery rings treated with $\mathrm{ONOO}(5 \mu \mathrm{M}$ peroxynitrite) showed an impairment of dilation (compared with $5.5 \mathrm{mM}$ D-glucose and $5 \mu \mathrm{M}$ decomposed peroxynitrite) in response to $1 \mu \mathrm{M}$ forskolin (adenylyl cyclase activator); this impairment was partially reversed by urate, C3 transferase, and Y-27632. Data are shown as mean $\pm \mathrm{SD}(n=6) .{ }^{*} P<0.05$ vs. ONOO

mimicked the effects of high glucose, and these actions of exogenous peroxynitrite were partially inhibited by urate (Fig. 6d-f).

mRNA and protein expressions of $\mathrm{K}_{\mathrm{v}} 1.2$ and $\mathrm{K}_{\mathrm{v}} 1.5$ are not affected by exogenous peroxynitrite

To investigate whether the functional impairment of vascular ring contraction/relaxation by high glucose might involve peroxynitrite-mediated changes in the expressions of $K_{v}$, the mRNA and protein expression of $K_{v} 1.2$ and $K_{v} 1.5$ were determined. As shown in Fig. 7, exogenous peroxynitrite $(5 \mu \mathrm{M})$ had no significant effects on the mRNA and protein expression of $\mathrm{K}_{\mathrm{v}} 1.2$ and $\mathrm{K}_{\mathrm{v}} 1.5(n=5)$.

\section{Exogenous peroxynitrite induces 3-NT-modification of proteins}

Exogenous peroxynitrite $(5 \mu \mathrm{M})$ caused significant increases in the levels of 3-NT-modified RhoA, ROCK1, ROCK2, and $\mathrm{K}_{\mathrm{v}} 1.2(P<0.05 ; n=5$; Fig. 8). However, no effect on $\mathrm{K}_{\mathrm{v}} 1.5$ was observed (Fig. 8).

\section{Discussion}

The aim of the present study was to explore whether the RhoA/ROCK signaling pathway is involved in mediating 


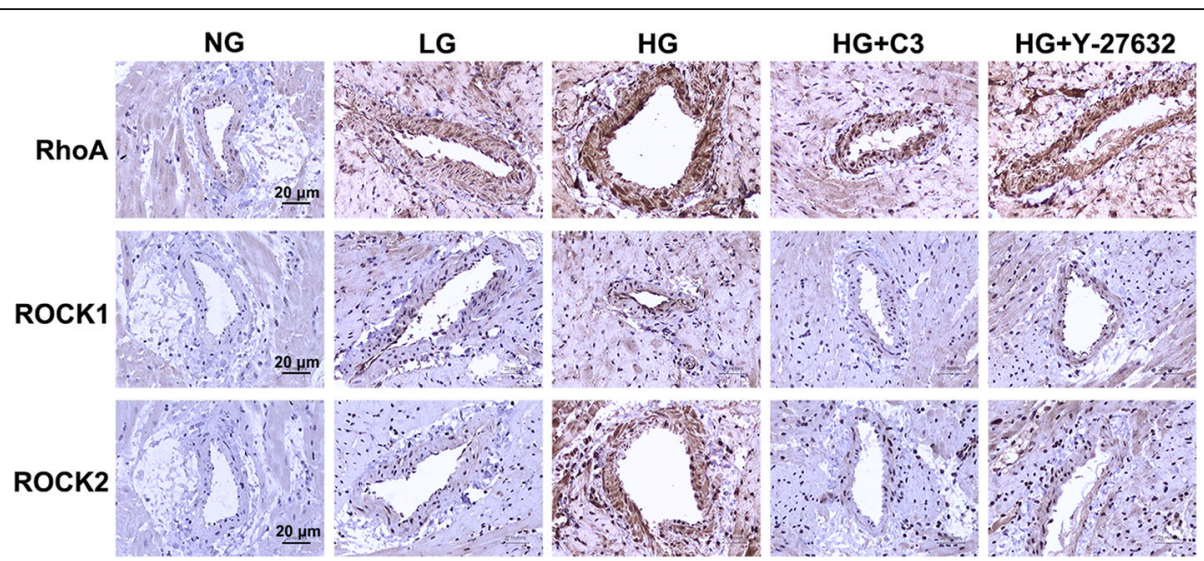

Fig. 2 Immunohistochemistry showing protein expressions of RhOA, ROCK1, and ROCK2 in rat coronary small coronary artery rings. Sections were stained with rabbit primary antibodies against RhoA, ROCK1, or ROCK2, followed by goat anti-rabbit biotinylated secondary antibody, and then visualized with diaminobenzidine. Sections were counterstained with hematoxylin and eosin. Brown staining in the image is indicative of expression of the protein of interest. Treatment with high glucose (23 mM D-glucose) was associated with enhanced expressions of RhoA, ROCK1, and ROCK2 compared with normal glucose (5.5 mM). These effects of high glucose were partially reversed by C3 transferase (a RhoA inhibitor) and Y-27632 (a ROCK inhibitor). NG: 5.5 mM glucose; HG:

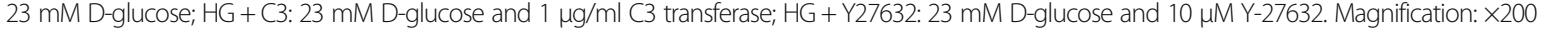

peroxynitrite-induced impairment of rat small coronary arteries. The main findings were that short-term exposure to high glucose and peroxynitrite caused functional impairment of rat small coronary artery rings that was partially reversed by RhoA or ROCK inhibition, and enhancement of RhoA, ROCK1, and ROCK2 activity. Therefore, increased RhoA, ROCK1, and ROCK2 expression and/or activities may contribute to peroxynitriteinduced coronary vascular dysfunction. Although the underlying mechanisms remain to be established, the effects of peroxynitrite may involve 3-NT modification of RhoA, ROCK1, ROCK2, and/or other proteins, which in turn enhances RhoA/ROCK signaling. Vascular ring increase in constrictor tone to 4-AP treatment was smaller in $\mathrm{HG}$ and peroxynitrite-treated vessels, meaning that $\mathrm{Kv}$ channels contribute less to the maintenance of dilator tone in HG or peroxynitrite incubated vessels than in NG vessels.

The interaction of $\mathrm{NO}$ with superoxide reduces $\mathrm{NO}$ availability (which contributes to coronary vascular dysfunction) and generates peroxynitrite that causes nitration of various proteins $[5,6,9]$. Increased 3-NT formation has been observed in an animal model of DM [10], and peroxynitrite has been suggested to target subcellular compartments in vascular endothelium [37]. Interestingly, the enzymes involved in $\mathrm{NO}$ synthesis are compartmentalized in caveolae [38], and the impairment of flow-mediated dilation of small coronary arteries in patients with DM may be due to disruption of caveolae by peroxynitrite and hence endothelial NOS uncoupling [39]. Our observations that peroxynitrite mimicked the effects of high glucose (in terms of coronary arteriolar dysfunction) suggest that nitration of cellular proteins contributes to the detrimental effects of DM on the coronary circulation, but these findings must be taken with caution because there was no endothelial contribution in the present study.

RhoA/ROCK signaling is involved in numerous cellular processes, and may play a role in several pathological conditions $[16,17]$. Various studies have reported that DM increases the expression and activity of RhoA and ROCK [27-33], consistent with the effects of HG observed in the present study. Both ROCK1 and ROCK2 are expressed in vascular endothelial and smooth muscle cells [33, 40]. In models of DM, ROCK inhibition improves microvascular damage, enhances cerebral vasodilation, reverses vasoconstriction, and improves coronary dysfunction through an enhancement of endothelial NOS [26, 27, 32, 33, 41, 42]. An impairment of endothelial NOS by RhoA and ROCK inhibitors would mitigate against peroxynitrite-induced disruption of caveolae and endothelial NOS uncoupling [39], potentially underlying our observations that C3 transferase and Y-27632 attenuated peroxynitrite-induced vascular dysfunction. But again, the effect of endothelium could not be assessed in the present study, and additional observations are necessary.

The findings that impaired vascular function and increased RhoA, ROCK1, and ROCK2 expression/activity occurred after only a 24-h exposure to HG imply that activation of the RhoA/ROCK pathway is an early event in the pathogenesis of diabetic complications. Endothelialdependent vasodilation is compromised during the early stages of DM [11,43]. Interestingly, in a rat model of early-stage DM, there was a trend toward upregulation of ROCK1 and ROCK2 expression, and a larger effect of ROCK inhibition (with fasudil) in the presence of NOS and cyclooxygenase blockade; furthermore, fasudil inhibited the occurrence of focal and segmental constrictions 


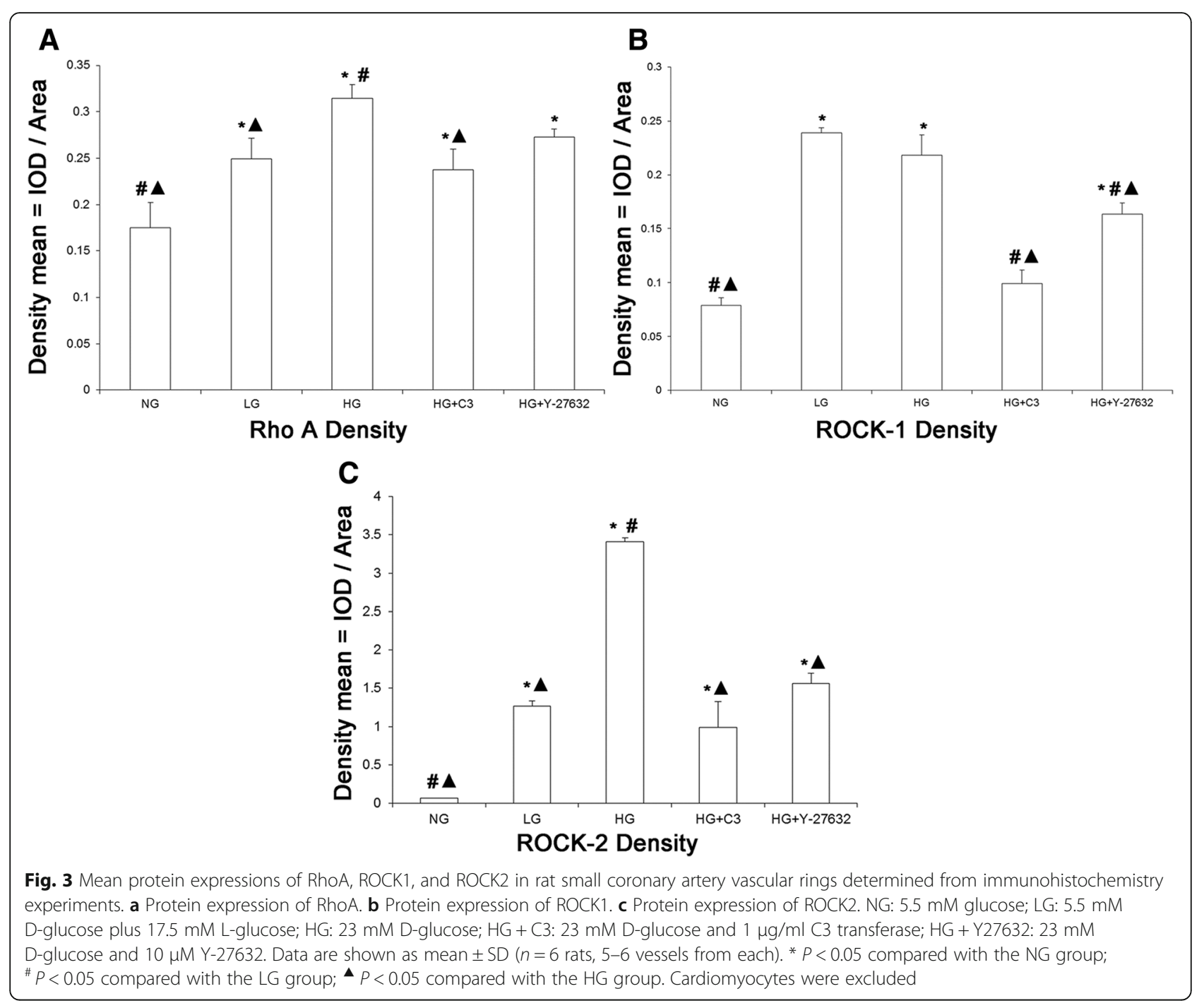

[44]. The involvement of RhoA/ROCK signaling in the early stages of DM would make ROCK a promising therapeutic target for treating diabetic complications $[16,45]$.

Hyperglycemia has been suggested to stimulate RhoA/ ROCK signaling through the generation of reactive oxygen species (ROS) [46]. Interestingly, peroxynitrite may be a mediator of enhanced ROCK signaling in endothelial cells [40, 47], in agreement with the present findings. Although the mechanisms remain unclear, peroxynitrite and the Rho/ROCK pathway may interact via a positive feedback loop, as has been proposed for the relationship between Rho/ROCK, protein kinase C- $\beta_{2}\left(\mathrm{PKC} \beta_{2}\right)$, inducible NOS (iNOS), and ROS. PKC $\beta_{2}[48]$ is believed to contribute to diabetic complications, and inhibitors of this kinase can improve DM-induced retinopathy, cardiomyopathy, nephropathy, and neuropathy [49, 50]. Hyperglycemia is thought to activate $\mathrm{PKC} \beta_{2}$, which in turn activates iNOS and RhoA/ROCK signaling [51-53]. $\quad \mathrm{PKC} \beta_{2}$ inhibition reduces iNOS-mediated cardiovascular abnormalities in diabetic rats [52]. iNOS may contribute to enhanced RhoA and ROCK expressions/activities; consistent with our observations, ROCK inhibition can downregulate RhoA expression [53]. Rats with experimental DM show increases in cardiac ROCK2 expression and $P K C \beta_{2}$ expression and activity; intriguingly, ROCK2 appears to directly interact with and activate $P K C \beta_{2}$ through phosphorylation at the T641 site [51]. Thus, RhoA/ ROCK may contribute to cardiac dysfunction in DM by activating $P K C \beta_{2}$ and generating ROS, through a positive-feedback loop involving iNOS [54]. ROS may contribute to the $\mathrm{PKC} \beta_{2}$ activation [55] and iNOS upregulation [56], while the effects of $\mathrm{PKC} \beta_{2}$ may, in part, be mediated by ROS [57, 58] and induction of iNOS [52]. Further research is required to establish whether peroxynitrite-induced activation of the RhoA/ROCK pathway leads to alterations in NO signaling (such as iNOS induction) that exacerbate the generation of peroxynitrite. 

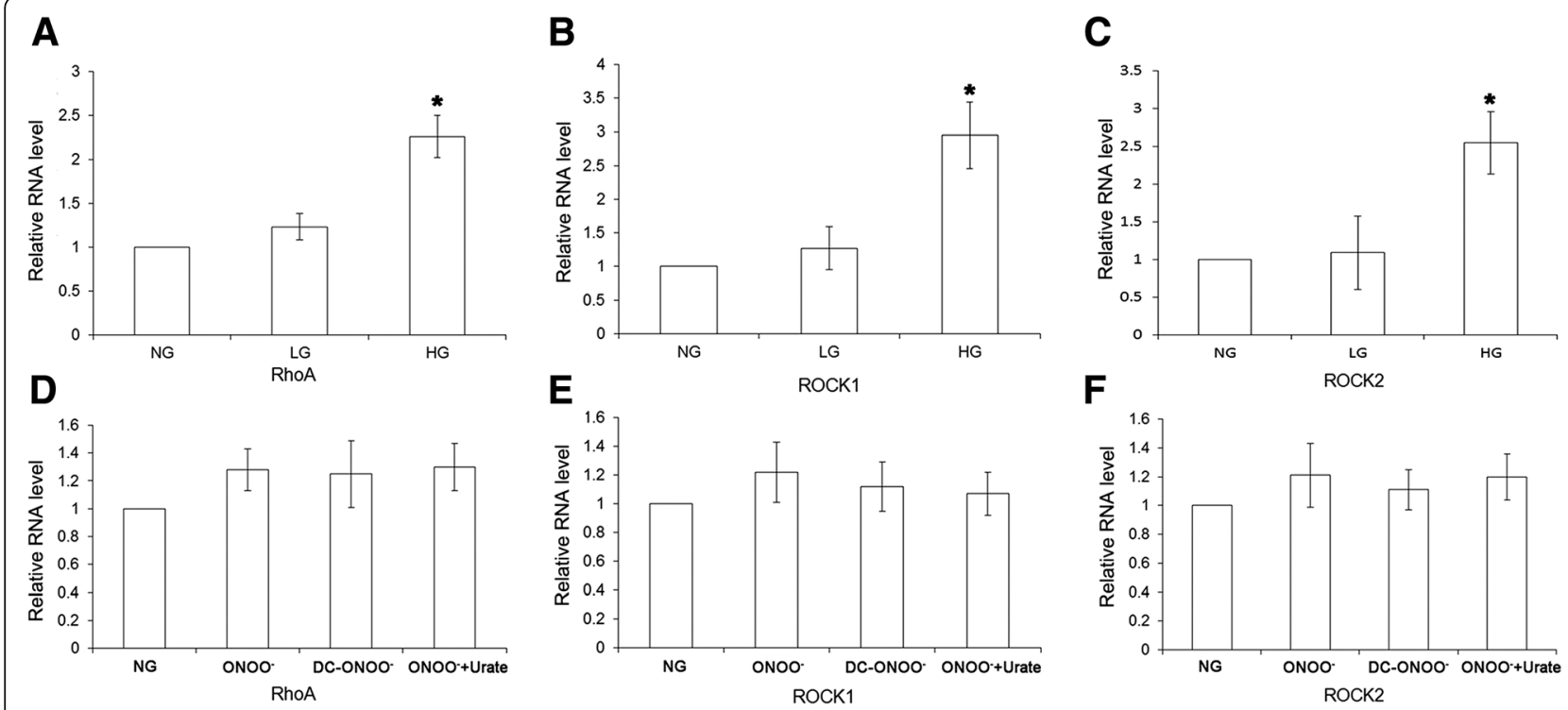

Fig. 4 mRNA expressions of RhoA, ROCK1, and ROCK2 in rat coronary vascular smooth muscle cells. mRNA expression was determined using real-time PCR. Treatment with high glucose (23 mM D-glucose) resulted in an increase in the mRNA expression of RhoA (a), ROCK1 (b), and ROCK2 (c). However, exogenous peroxynitrite was without significant effect on the mRNA expression of RhoA (d), ROCK1 (e), and ROCK2 (f). NG: 5.5 mM glucose; LG: 5.5 mM D-glucose plus 17.5 mM L-glucose; HG: 23 mM D-glucose; ONOO: $5 \mu$ M peroxynitrite; DC-ONOO: $5 \mu M$ decomposed peroxynitrite; ONOO + Urate: $5 \mu \mathrm{M}$ peroxynitrite and $100 \mu \mathrm{M}$ urate (to scavenge peroxynitrite). Data are shown as mean \pm SD $(n=5) .{ }^{*} P<0.05$ compared with the NG group

In addition, other signaling mechanisms may be involved in alterations to NO signaling, such as the JNK and TGF $\beta /$ SMAD pathways [59].

$\mathrm{K}_{\mathrm{V}}$ are involved in the regulation of vascular tone by limit membrane depolarization [35]. A recent study has shown that diabetes led to reduced presence of $\mathrm{K}_{\mathrm{V}} 1.2$ in nerves from diabetic mice and diabetic patients [60]. Another study suggests that diabetes might be associated with gender-specific decreases in $\mathrm{K}_{\mathrm{V}} 1.5$ levels in myocytes from male mice, and that this effect might be triggered by the renin-angiotensin system [61]. In the present study, exogenous peroxynitrite had no significant effects on the mRNA and protein expression of $K_{v} 1.2$ and $K_{v} 1.5$, but significantly increased the levels of 3-NT-modified $K_{v} 1.2$. A previous study revealed that excess peroxynitrite production might impair $\mathrm{K}_{\mathrm{V}}$ function in DM, which is consistent with the present study [62]. Another study has shown that peroxynitrite overproduction induced by high glucose impaired $\mathrm{K}_{\mathrm{V}}$-mediated vascular dilation mediated by cAMP [63]. 4-AP is a
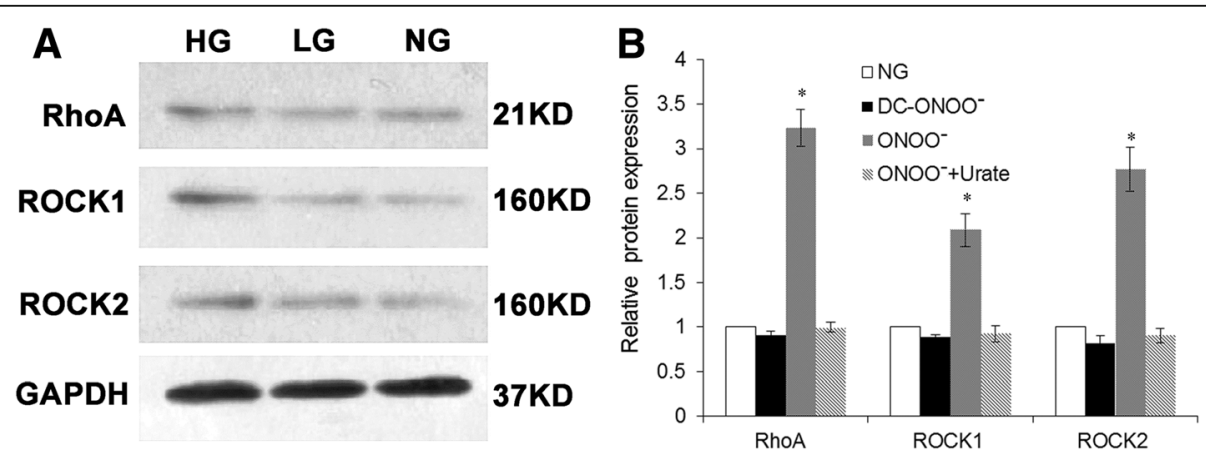

Fig. 5 Protein expressions of RhoA, ROCK1 and ROCK2 in rat coronary vascular smooth muscle cells. Protein expression was determined using the Western blot technique. a Representative blots for RhoA, ROCK1, and ROCK2; GAPDH expression was used as an internal reference. b Mean data for protein expression levels. Treatment with peroxynitrite was associated with enhanced the expression of RhoA, ROCK1, and ROCK2 compared with controls. NG: 5.5 mM glucose; LG: 5.5 mM D-glucose plus 17.5 mM L-glucose; HG: 23 mM D-glucose. Data are shown as mean \pm SD $(n=5)$. * $P<0.05$ compared with the NG group 

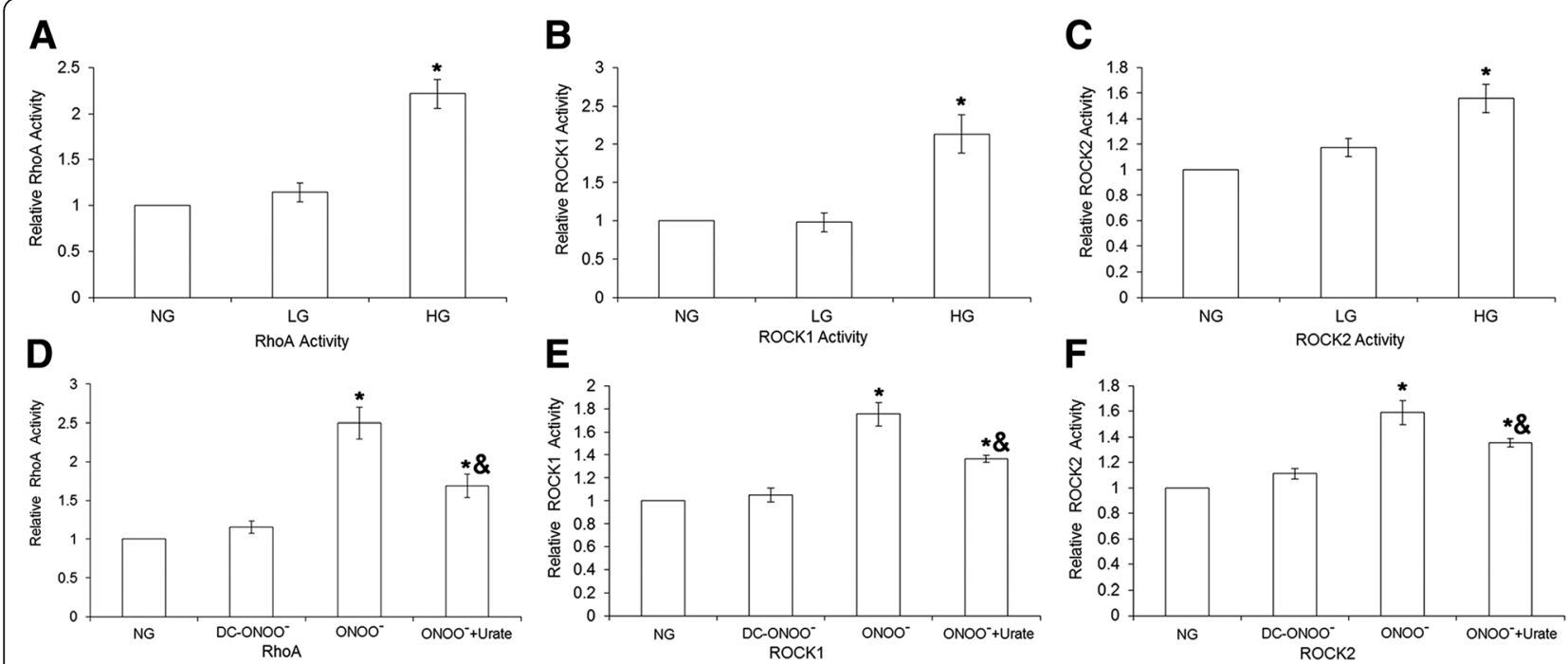

Fig. 6 RhoA, ROCK1, and ROCK2 activities in rat coronary vascular smooth muscle cells. RhoA activation was measured using the luminescencebased G-LISA Activation Assay kit; ROCK1 and ROCK2 activities were detected using the Genmed Kinase Activity Spectroscopy Kit. Treatment with high glucose (23 mM D-glucose) resulted in an increase in the activities of RhoA (a), ROCK1 (b), and ROCK2 (c). Similarly, treatment with $5 \mu M$ peroxynitrite was associated with increases in RhoA (a), ROCK1 (b), and ROCK2 (c) activities; these effects could be partially inhibited by $100 \mu \mathrm{M}$ urate (a scavenger of peroxynitrite). NG: $5.5 \mathrm{mM}$ glucose; LG: $5.5 \mathrm{mM}$ D-glucose plus $17.5 \mathrm{mM}$ L-glucose; HG: 23 mM D-glucose; ONOO-: 5 M peroxynitrite; DC-ONOO: $5 \mu \mathrm{M}$ decomposed peroxynitrite; ONOO + Urate: $5 \mu \mathrm{M}$ peroxynitrite and $100 \mu \mathrm{M}$ urate (to scavenge peroxynitrite). Data are shown as mean $\pm \mathrm{SD}(n=5) .{ }^{*} P<0.05$ compared with the NG group; ${ }^{\&} P<0.05$ compared with the ONOO ${ }^{-}$group

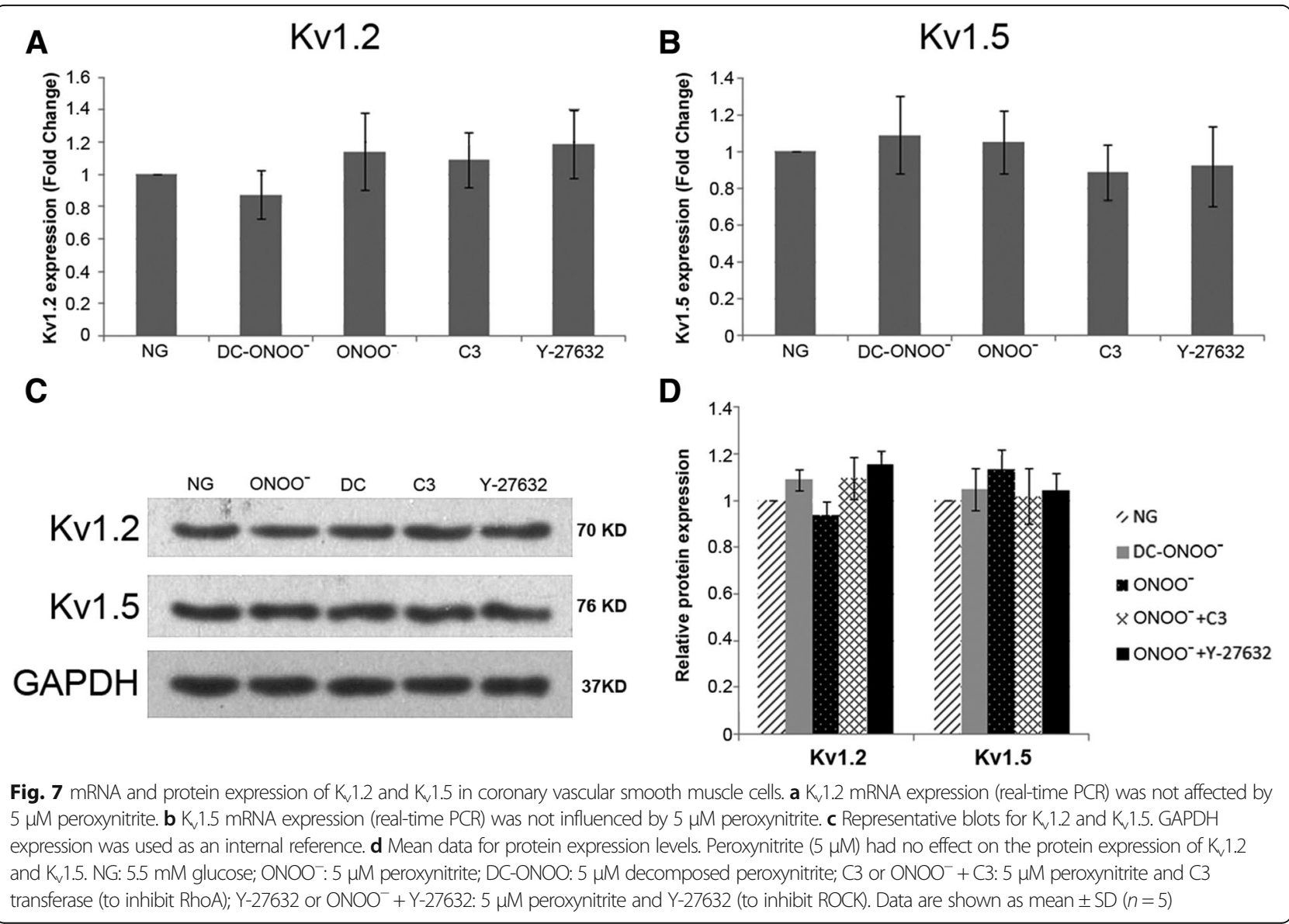




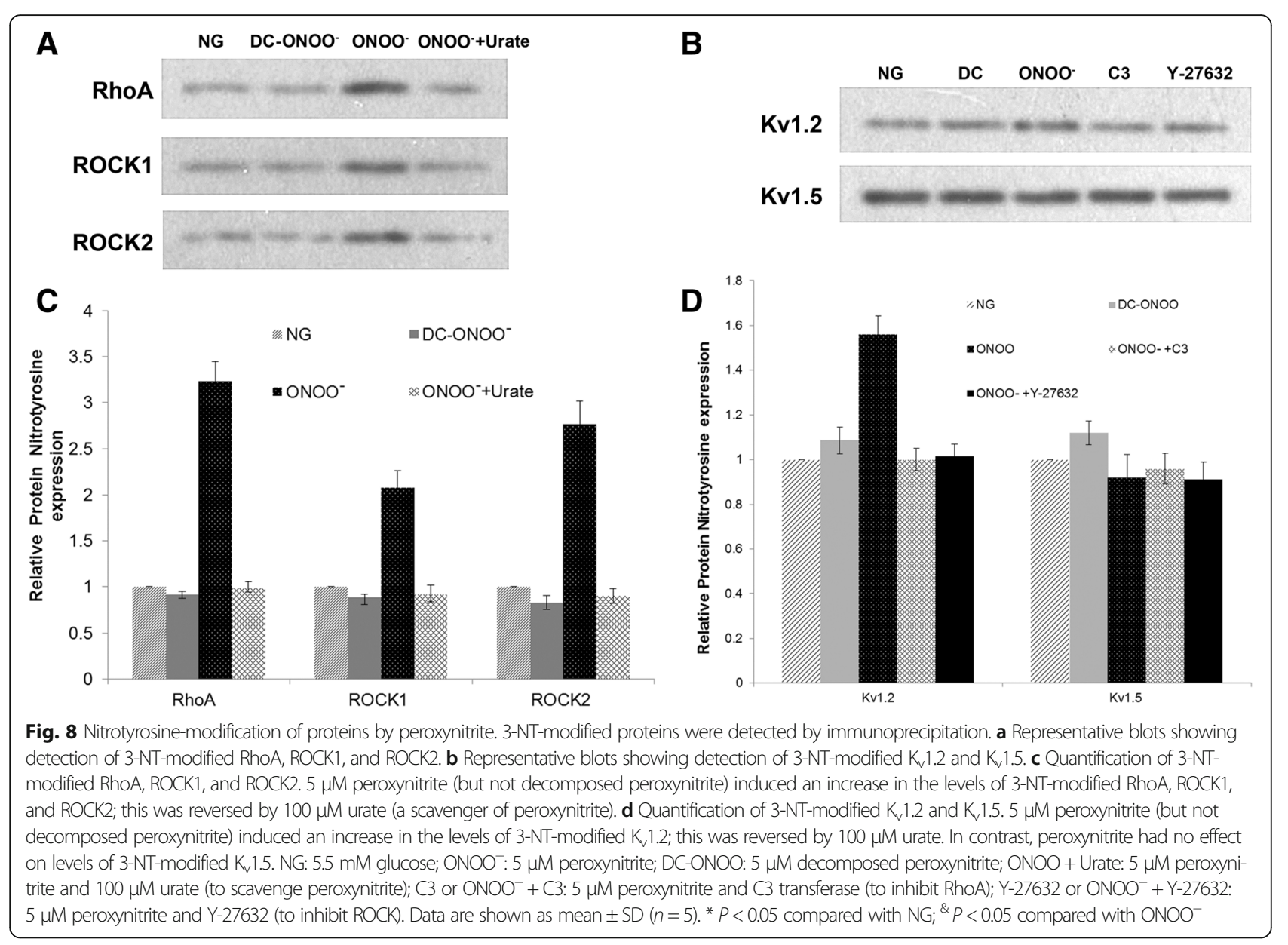

$K_{V}$ blocker that allow the separation of the effects of $K_{V}$ and $\mathrm{Ca}^{2+}$-activated $\mathrm{K}^{+}$channels [35]. In the present study, 4-AP decreased the contraction response to a greater extent in glucose-treated rings compared with controls. Forskolin is an activator of adenylyl cyclase, leading to an increase in intracellular cAMP levels. The decreased vasorelaxation observed in the present study also point toward a role of $\mathrm{K}_{\mathrm{V}}$ in the process of impaired vascular response in DM. Taken together, these results suggest that $K_{v}$ channels contribute less to the maintenance of dilator tone in $\mathrm{HG}$ or peroxynitrite incubated vessels than in NG vessels. However, further study is necessary to adequately assess the role and exact mechanisms of $K_{V}$ in DM and vascular dysfunction.

\section{Conclusions}

Vascular ring increase in constrictor tone to 4-AP treatment was smaller in HG and peroxynitrite-treated vessels, meaning that $\mathrm{Kv}$ channels contribute less to the maintenance of dilator tone in HG or peroxynitrite incubated vessels than in NG vessels, possibly via 3-NT modification of RhoA, ROCK1, ROCK2, KV1.2, and/or other proteins. Importantly, these results suggest that even a short-term exposure to glucose was might be sufficient to induce this impaired response.

\section{Abbreviations}

ANOVA: Analysis of variance; BSA: Bovine serum albumin;

DAB: Diaminobenzidine; DM: Diabetes mellitus; DMEM: Dulbecco's modified Eagle's medium; FBS: Fetal bovine serum; H\&E: Hematoxylin and eosin; HG: High glucose; iNOS: Inducible NOS; LG: L-glucose; NG: Normal glucose; NO: Nitric oxide; NOS: NO synthase; PCR: Polymerase chain reaction; PKC 32 : Protein kinase C- $\beta 2$; ROCK: RhoA-associated protein kinase; ROS: Reactive oxygen species; SD: Standard deviation; VSMCs: Vascular smooth muscle cells

\section{Acknowledgements \\ None}

\section{Funding}

This research was supported by the National Natural Science Foundation of China (Grant NO. 30971240) (http://www.nsfc.gov.cn/).

\section{Availability of data and materials}

The dataset(s) supporting the conclusions of this article is (are) included within the article.

\section{Authors' contributions}

ZS contributed to study design and drafting the manuscript. XW, WL, HP, XS, $L M$, HL contributed to to acquisition of data, or analysis and interpretation of data. HL contributed to revising it critically for important intellectual content. All authors have given final approval of the version to be published. 


\section{Competing interests}

The authors declare that they have no competing interests.

\section{Consent for publication}

Not applicable.

\section{Ethics approval and consent to participate}

The study was approved by the Animal Care and Use Committee of Beijing Friendship Hospital, Capital Medical University (Beijing, China).

\section{Author details}

'Department of Heart Center, Capital Medical University Affiliated Beijing Friendship Hospital, Beijing, China. ${ }^{2}$ Beijing Key Laboratory of Metabolic Disturbance Related Cardiovascular Disease, Beijing, People's Republic of China.

Received: 8 April 2016 Accepted: 28 September 2016 Published online: 11 October 2016

\section{References}

1. Nahser Jr PJ, Brown RE, Oskarsson H, Winniford MD, Rossen JD. Maximal coronary flow reserve and metabolic coronary vasodilation in patients with diabetes mellitus. Circulation. 1995:91(3):635-40.

2. Prior JO, Quinones MJ, Hernandez-Pampaloni M, Facta AD, Schindler TH, Sayre JW, et al. Coronary circulatory dysfunction in insulin resistance, impaired glucose tolerance, and type 2 diabetes mellitus. Circulation. 2005; 111(18):2291-8. doi:10.1161/01.CIR.0000164232.62768.51.

3. Yonaha O, Matsubara T, Naruse K, Ishii H, Murohara T, Nakamura J, et al. Effects of reduced coronary flow reserve on left ventricular function in type 2 diabetes. Diabetes Res Clin Pract. 2008;82(1):98-103. doi:10.1016/j.diabres. 2008.06.020.

4. Jenkins MJ, Edgley AJ, Sonobe T, Umetani K, Schwenke DO, Fujii Y, et al. Dynamic synchrotron imaging of diabetic rat coronary microcirculation in vivo. Arterioscler Thromb Vasc Biol. 2012;32(2):370-7. doi:10.1161/ATVBAHA. 111.237172 .

5. Bagi Z, Koller A, Kaley G. Superoxide-NO interaction decreases flow- and agonist-induced dilations of coronary arterioles in type 2 diabetes mellitus. Am J Physiol Heart Circ Physiol. 2003;285(4):H1404-10. doi:10.1152/ajpheart. 00235.2003.

6. Bagi Z, Koller A, Kaley G. PPARgamma activation, by reducing oxidative stress, increases $\mathrm{NO}$ bioavailability in coronary arterioles of mice with type 2 diabetes. Am J Physiol Heart Circ Physiol. 2004;286(2):H742-8. doi:10.1152/ ajpheart.00718.2003.

7. Forbes JM, Cooper ME. Mechanisms of diabetic complications. Physiol Rev. 2013;93(1):137-88. doi:10.1152/physrev.00045.2011.

8. Forstermann U, Sessa WC. Nitric oxide synthases: regulation and function. Eur Heart J. 2012;33(7):829-37. doi:10.1093/eurheartj/ehr30. 37a-37d.

9. Sharma A, Bernatchez PN, de Haan JB. Targeting endothelial dysfunction in vascular complications associated with diabetes. Int J Vasc Med. 2012;2012: 750126. doi:10.1155/2012/750126

10. Li H, Gutterman DD, Rusch NJ, Bubolz A, Liu Y. Nitration and functional loss of voltage-gated $\mathrm{K}+$ channels in rat coronary microvessels exposed to high glucose. Diabetes. 2004;53(9):2436-42.

11. El-Remessy AB, Tawfik HE, Matragoon S, Pillai B, Caldwell RB, Caldwell RW. Peroxynitrite mediates diabetes-induced endothelial dysfunction: possible role of Rho kinase activation. Exp Diabetes Res. 2010;2010:247861. doi:10. 1155/2010/247861.

12. Pacher P, Szabo C. Role of peroxynitrite in the pathogenesis of cardiovascular complications of diabetes. Curr Opin Pharmacol. 2006;6(2): 136-41. doi:10.1016/j.coph.2006.01.001.

13. Romero MJ, Platt DH, Tawfik HE, Labazi M, El-Remessy AB, Bartoli M, et al. Diabetes-induced coronary vascular dysfunction involves increased arginase activity. Circ Res. 2008;102(1):95-102. doi:10.1161/CIRCRESAHA.107.155028.

14. Szabo C, Zanchi A, Komjati K, Pacher P, Krolewski AS, Quist WC, et al. Poly(ADP-Ribose) polymerase is activated in subjects at risk of developing type 2 diabetes and is associated with impaired vascular reactivity. Circulation. 2002;106(21):2680-6.

15. Nakagawa O, Fujisawa K, Ishizaki T, Saito Y, Nakao K, Narumiya S. ROCK-I and ROCK-II, two isoforms of Rho-associated coiled-coil forming protein serine/ threonine kinase in mice. FEBS Lett. 1996;392(2):189-93.
16. Zhou H, Li YJ. Rho kinase inhibitors: potential treatments for diabetes and diabetic complications. Curr Pharm Des. 2012;18(20):2964-73.

17. Nunes KP, Rigsby CS, Webb RC. RhoA/Rho-kinase and vascular diseases: what is the link? Cell Mol Life Sci. 2010;67(22):3823-36. doi:10.1007/s00018010-0460-1.

18. Chitaley K, Weber D, Webb RC. RhoA/Rho-kinase, vascular changes, and hypertension. Curr Hypertens Rep. 2001;3(2):139-44.

19. Mukai Y, Shimokawa H, Matoba T, Kandabashi T, Satoh S, Hiroki J, et al. Involvement of Rho-kinase in hypertensive vascular disease: a novel therapeutic target in hypertension. FASEB J. 2001;15(6):1062-4.

20. Morishige K, Shimokawa H, Eto Y, Kandabashi T, Miyata K, Matsumoto Y, et al. Adenovirus-mediated transfer of dominant-negative rho-kinase induces a regression of coronary arteriosclerosis in pigs in vivo. Arterioscler Thromb Vasc Biol. 2001;21(4):548-54.

21. Shibuya M, Hirai S, Seto M, Satoh S, Ohtomo E, Fasudil Ischemic Stroke Study $\mathrm{G}$. Effects of fasudil in acute ischemic stroke: results of a prospective placebo-controlled double-blind trial. J Neurol Sci. 2005;238(1-2):31-9. doi: 10.1016/j.jns.2005.06.003.

22. Kandabashi $T$, Shimokawa $H$, Miyata $K$, Kunihiro I, Eto $Y$, Morishige $K$, et al. Evidence for protein kinase C-mediated activation of Rho-kinase in a porcine model of coronary artery spasm. Arterioscler Thromb Vasc Biol. 2003;23(12):2209-14. doi:10.1161/01.ATV.0000104010.87348.26.

23. Masumoto A, Mohri M, Shimokawa H, Urakami L, Usui M, Takeshita A. Suppression of coronary artery spasm by the Rho-kinase inhibitor fasudil in patients with vasospastic angina. Circulation. 2002;105(13):1545-7.

24. Hamid SA, Bower HS, Baxter GF. Rho kinase activation plays a major role as a mediator of irreversible injury in reperfused myocardium. Am J Physiol Heart Circ Physiol. 2007;292(6):H2598-606. doi:10.1152/ajpheart.01393.2006.

25. Kishi T, Hirooka Y, Masumoto A, Ito K, Kimura Y, Inokuchi K, et al. Rho-kinase inhibitor improves increased vascular resistance and impaired vasodilation of the forearm in patients with heart failure. Circulation. 2005;111(21):2741-7. doi:10.1161/CIRCULATIONAHA.104.510248.

26. Kobayashi N, Horinaka S, Mita S, Nakano S, Honda T, Yoshida K, et al. Critical role of Rho-kinase pathway for cardiac performance and remodeling in failing rat hearts. Cardiovasc Res. 2002;55(4):757-67.

27. Arita R, Hata Y, Nakao S, Kita T, Miura M, Kawahara S, et al. Rho kinase inhibition by fasudil ameliorates diabetes-induced microvascular damage. Diabetes. 2009;58(1):215-26. doi:10.2337/db08-0762.

28. Budzyn K, Marley PD, Sobey CG. Targeting Rho and Rho-kinase in the treatment of cardiovascular disease. Trends Pharmacol Sci. 2006;27(2):97104. doi:10.1016/j.tips.2005.12.002.

29. Cicek FA, Kandilci HB, Turan B. Role of ROCK upregulation in endothelial and smooth muscle vascular functions in diabetic rat aorta. Cardiovasc Diabetol. 2013;12:51. doi:10.1186/1475-2840-12-51.

30. Failli P, Alfarano C, Franchi-Micheli S, Mannucci E, Cerbai E, Mugelli A, et al. Losartan counteracts the hyper-reactivity to angiotensin II and ROCK1 overactivation in aortas isolated from streptozotocin-injected diabetic rats. Cardiovasc Diabetol. 2009;8:32. doi:10.1186/1475-2840-8-32.

31. Miao L, Calvert JW, Tang J, Zhang JH. Upregulation of small GTPase RhoA in the basilar artery from diabetic (mellitus) rats. Life Sci. 2002;71(10):1175-85.

32. Noma K, Oyama N, Liao JK. Physiological role of ROCKs in the cardiovascular system. Am J Physiol Cell Physiol. 2006;290(3):C661-8. doi:10.1152/ajpcell.00459.2005.

33. Nuno DW, Harrod JS, Lamping KG. Sex-dependent differences in Rho activation contribute to contractile dysfunction in type 2 diabetic mice. Am J Physiol Heart Circ Physiol. 2009;297(4):H1469-77. doi:10.1152/ajpheart.00407.2009.

34. Sobey CG. Potassium channel function in vascular disease. Arterioscler Thromb Vasc Biol. 2001:21(1):28-38

35. Ko EA, Han J, Jung ID, Park WS. Physiological roles of K+ channels in vascular smooth muscle cells. J Smooth Muscle Res. 2008:44(2):65-81.

36. Beckman JS, Beckman TW, Chen J, Marshall PA, Freeman BA. Apparent hydroxyl radical production by peroxynitrite: implications for endothelial injury from nitric oxide and superoxide. Proc Natl Acad Sci. 1990;87(4):1620-4.

37. Pacher P, Beckman JS, Liaudet L. Nitric oxide and peroxynitrite in health and disease. Physiol Rev. 2007:87(1):315-424. doi:10.1152/physrev.00029.2006.

38. Cohen AW, Hnasko R, Schubert W, Lisanti MP. Role of caveolae and caveolins in health and disease. Physiol Rev. 2004:84(4):1341-79. doi:10. 1152/physrev.00046.2003.

39. Cassuto J, Dou H, Czikora I, Szabo A, Patel VS, Kamath V, et al. Peroxynitrite disrupts endothelial caveolae leading to eNOS uncoupling and diminished flow-mediated dilation in coronary arterioles of diabetic patients. Diabetes. 2014;63(4):1381-93. doi:10.2337/db13-0577. 
40. Ming XF, Barandier C, Viswambharan H, Kwak BR, Mach F, Mazzolai L, et al. Thrombin stimulates human endothelial arginase enzymatic activity via RhoA/ROCK pathway: implications for atherosclerotic endothelial dysfunction. Circulation. 2004; 110(24):3708-14. doi:10.1161/01.CIR.0000142867.26182.32.

41. Didion SP, Lynch CM, Baumbach GL, Faraci FM. Impaired endothelium-dependent responses and enhanced influence of Rho-kinase in cerebral arterioles in type II diabetes. Stroke. 2005;36(2):342-7. doi:10.1161/01.STR.0000152952.42730.92.

42. Matsumoto T, Kobayashi T, Ishida K, Taguchi K, Kamata K. Enhancement of mesenteric artery contraction to 5-HT depends on Rho kinase and Src kinase pathways in the ob/ob mouse model of type 2 diabetes. $\mathrm{Br} \mathrm{J}$ Pharmacol. 2010;160(5):1092-104. doi:10.1111/j.1476-5381.2010.00753.x

43. Tawfik HE, El-Remessy AB, Matragoon S, Ma G, Caldwell RB, Caldwell RW Simvastatin improves diabetes-induced coronary endothelial dysfunction. J Pharmacol Exp Ther. 2006;319(1):386-95. doi:10.1124/jpet.106.106823.

44. Pearson JT, Jenkins MJ, Edgley AJ, Sonobe T, Joshi M, Waddingham MT, et al. Acute Rho-kinase inhibition improves coronary dysfunction in vivo, in the early diabetic microcirculation. Cardiovasc Diabetol. 2013;12:111. doi:10. 1186/1475-2840-12-111.

45. Surma M, Wei L, Shi J. Rho kinase as a therapeutic target in cardiovascular disease. Future Cardiol. 2011;7(5):657-71. doi:10.2217/fca.11.51.

46. Bailey SR, Mitra S, Flavahan S, Flavahan NA. Reactive oxygen species from smooth muscle mitochondria initiate cold-induced constriction of cutaneous arteries. Am J Physiol Heart Circ Physiol. 2005;289(1):H243-50. doi:10.1152/ ajpheart.01305.2004.

47. Chandra S, Romero MJ, Shatanawi A, Alkilany AM, Caldwell RB, Caldwell RW Oxidative species increase arginase activity in endothelial cells through the RhoA/Rho kinase pathway. Br J Pharmacol. 2012;165(2):506-19. doi:10.1111/j. 1476-5381.2011.01584.x.

48. Reyland ME. Protein kinase C isoforms: Multi-functional regulators of cell life and death. Front Biosci (Landmark Ed). 2009;14:2386-99.

49. Avignon A, Sultan A. PKC-B inhibition: a new therapeutic approach for diabetic complications? Diabetes Metab. 2006:32(3):205-13.

50. Danis RP, Sheetz MJ. Ruboxistaurin: PKC-beta inhibition for complications of diabetes. Expert Opin Pharmacother. 2009;10(17):2913-25. doi:10.1517/ 14656560903401620.

51. Lin G, Brownsey RW, Macleod KM. Complex regulation of PKCbeta2 and PDK-1/AKT by ROCK2 in diabetic heart. PLoS One. 2014;9(1):e86520. doi:10. 1371/journal.pone.0086520.

52. Nagareddy PR, Soliman H, Lin G, Rajput PS, Kumar U, McNeill JH, et al. Selective inhibition of protein kinase $\mathrm{C}$ beta(2) attenuates inducible nitric oxide synthase-mediated cardiovascular abnormalities in streptozotocininduced diabetic rats. Diabetes. 2009;58(10):2355-64. doi:10.2337/db09-0432.

53. Soliman H, Craig GP, Nagareddy P, Yuen VG, Lin G, Kumar U, et al. Role of inducible nitric oxide synthase in induction of RhoA expression in hearts from diabetic rats. Cardiovasc Res. 2008;79(2):322-30. doi:10.1093/cvr/cvn095.

54. Soliman H, Gador A, Lu YH, Lin G, Bankar G, MacLeod KM. Diabetes-induced increased oxidative stress in cardiomyocytes is sustained by a positive feedback loop involving Rho kinase and PKCbeta2. Am J Physiol Heart Circ Physiol. 2012;303(8):H989-H1000. doi:10.1152/ajpheart.00416.2012.

55. Xia Z, Kuo KH, Nagareddy PR, Wang F, Guo Z, Guo T, et al. N-acetylcysteine attenuates PKCbeta2 overexpression and myocardial hypertrophy in streptozotocin-induced diabetic rats. Cardiovasc Res. 2007;73(4):770-82. doi: 10.1016/j.cardiores.2006.11.033.

56. Zhen J, Lu H, Wang XQ, Vaziri ND, Zhou XJ. Upregulation of endothelial and inducible nitric oxide synthase expression by reactive oxygen species. Am J Hypertens. 2008;21(1):28-34. doi:10.1038/ajh.2007.14.

57. Liu Y, Lei S, Gao X, Mao X, Wang T, Wong GT, et al. PKCbeta inhibition with ruboxistaurin reduces oxidative stress and attenuates left ventricular hypertrophy and dysfunction in rats with streptozotocin-induced diabetes. Clin Sci (Lond). 2012;122(4):161-73. doi:10.1042/CS20110176.

58. Zhu LH, Wang L, Wang D, Jiang H, Tang QZ, Yan L, et al. Puerarin attenuates high-glucose-and diabetes-induced vascular smooth muscle cell proliferation by blocking PKCbeta2/Rac1-dependent signaling. Free Radic Biol Med. 2010;48(4):471-82. doi:10.1016/j.freeradbiomed.2009.10.040.

59. Zhou H, Li YJ, Wang M, Zhang LH, Guo BY, Zhao ZS, et al. Involvement of RhoA/ROCK in myocardial fibrosis in a rat model of type 2 diabetes. Acta Pharmacol Sin. 2011;32(8):999-1008. doi:10.1038/aps.2011.54.

60. Zenker J, Poirot O, de Preux Charles AS, Arnaud E, Medard JJ, Lacroix C, et al. Altered distribution of juxtaparanodal kv1.2 subunits mediates peripheral nerve hyperexcitability in type 2 diabetes mellitus. J Neurosci. 2012;32(22):7493-8. doi:10.1523/JNEUROSCI.0719-12.2012.
61. Shimoni Y, Chuang M, Abel ED, Severson DL. Gender-dependent attenuation of cardiac potassium currents in type 2 diabetic $\mathrm{db} / \mathrm{db}$ mice. J Physiol. 2004;555(Pt 2):345-54. doi:10.1113/jphysiol.2003.055590.

62. Bubolz AH, Wu Q, Larsen BT, Gutterman DD, Liu Y. Ebselen reduces nitration and restores voltage-gated potassium channel function in small coronary arteries of diabetic rats. Am J Physiol Heart Circ Physiol. 2007;293(4):H2231-7. doi:10.1152/ajpheart.00717.2007.

63. Li H, Chai Q, Gutterman DD, Liu Y. Elevated glucose impairs CAMP-mediated dilation by reducing Kv channel activity in rat small coronary smooth muscle cells. Am J Physiol Heart Circ Physiol. 2003;285(3):H1213-9. doi:10. 1152/ajpheart.00226.2003.

\section{Submit your next manuscript to BioMed Central and we will help you at every step:}

- We accept pre-submission inquiries

- Our selector tool helps you to find the most relevant journal

- We provide round the clock customer support

- Convenient online submission

- Thorough peer review

- Inclusion in PubMed and all major indexing services

- Maximum visibility for your research

Submit your manuscript at www.biomedcentral.com/submit
Biomed Central 